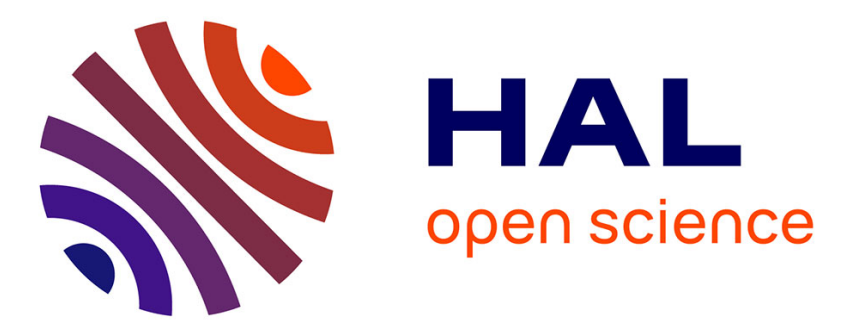

\title{
Discrepancies in Thorium Oxide Solubility Values: a New Experimental Approach to Improve Understanding of Oxide Surface at Solid/Solution Interface
} Johan Vandenborre, Abdesselam Abdelouas, Bernd Grambow

\section{- To cite this version:}

Johan Vandenborre, Abdesselam Abdelouas, Bernd Grambow. Discrepancies in Thorium Oxide Solubility Values: a New Experimental Approach to Improve Understanding of Oxide Surface at Solid/Solution Interface. Radiochimica Acta, 2008, 96, pp.515-520. 10.1524/ract.2008.1531 . in2p300291593

\section{HAL Id: in2p3-00291593 \\ https://hal.in2p3.fr/in2p3-00291593}

Submitted on 27 Jun 2008

HAL is a multi-disciplinary open access archive for the deposit and dissemination of scientific research documents, whether they are published or not. The documents may come from teaching and research institutions in France or abroad, or from public or private research centers.
L'archive ouverte pluridisciplinaire HAL, est destinée au dépôt et à la diffusion de documents scientifiques de niveau recherche, publiés ou non, émanant des établissements d'enseignement et de recherche français ou étrangers, des laboratoires publics ou privés. 


\title{
DISCREPANCIES IN THORIUM OXIDE SOLUBILITY VALUES: A NEW EXPERIMENTAL APPROACH TO IMPROVE UNDERSTANDING OF OXIDE SURFACE AT SOLID/SOLUTION INTERFACE
}

\author{
J.Vandenborre $^{1)^{*}}$, A.Abdelouas ${ }^{1)}$, B.Grambow ${ }^{1)}$ \\ 1) SUBATECH, Unité Mixte de Recherche 6457, École des mines de Nantes, CNRS/IN2P3, Université de Nantes, BP 20722, \\ 44307 Nantes cedex 3 France
}

\section{Summary}

The solubility of $\mathrm{ThO}_{2}(\mathrm{cr})$ was studied since many years but a large discrepancy in solubility values is noticed in the literature. The present work suggests that this discrepancy is related to differences in the surface properties of thorium oxide.

To understand the role of surface properties on solubility values, we conducted experiments with $\mathrm{ThO} \mathrm{O}_{2}(\mathrm{cr})$ spheres with reproducable surface properties. Batch dissolution experiments were conducted in $0.01 \mathrm{M}$ $\mathrm{NaCl}$ solution at $\mathrm{pH}=3.0$ and 4.0 for periods of time up to 270 days. The solutions were spiked with ${ }^{229} \mathrm{Th}$ to determine precipitation (sorption) rates of thorium, while dissolution rates were determined by measuring ${ }^{232} \mathrm{Th}$ released from $\mathrm{ThO}_{2}(\mathrm{cr})$ spheres. We assume that ${ }^{229} \mathrm{Th}$ atoms are exchanged only with active sites involved in Th-dissolution. Using ${ }^{229} \mathrm{Th}$ as local sensor of attachement and detachment processes at the $\mathrm{ThO}_{2}(\mathrm{cr})$ surface under close-to-equilibrium conditions, allows to assess surface reactivity of the solid during solubility experiments.

Keywords: $\mathrm{ThO}_{2}(\mathrm{cr})$, solubility, surface properties, solid/solution interface, dissolution properties

\footnotetext{
* Johan.Vandenborre@subatech.in2p3.fr 


\section{Introduction}

The dissolution properties and/or solubility equilibria of $\mathrm{ThO}_{2}(\mathrm{cr})$ [1-9], $\mathrm{Th}(\mathrm{OH})_{4}(\mathrm{am})$ and/or $\mathrm{ThO} \mathrm{O}_{2}(\mathrm{am}, \mathrm{hyd})[1$, 4, 6, 7, 9-13] were studied since many years. At neutral to basic $\mathrm{pH}$, solubilities of $\mathrm{ThO}_{2}(\mathrm{cr})$ and $\mathrm{Th}(\mathrm{OH})_{4}(\mathrm{am})$ are at a value between 1-10 $\mathrm{nM}$, whereas at acid $\mathrm{pH}$, the solubilites of these two forms differ by as much as 7 orders of magnitude. According to equilibrium thermodynamics, large discrepancies in solubilites should also persist at neutral $\mathrm{pH}$. The similarity of solubility values at neutral $\mathrm{pH}$ was then explained by the formation of a non-detectable amorphous surface phase on $\mathrm{ThO}_{2}(\mathrm{cr})$ [14]. A study of surface reactivity at close-to-equilibrium conditions may provide further insight in the processes controlling solubility. Kinetically, solubility equilibria can be interpreted as being governed by equal rates of attachment and detachment of surface species. These rates are not known under close-to-equilibrium conditions. If they are fast, rapid and continous reconstruction of the surface would be expected and amorphous products will easily become redissolved to become incorporated into the crystalline surface. In contrast, if these rates are slow, amorphous products may survive and even in the absence of amorphous products, high energy surface sites may control overall solids solubility. The present work is carried out to shed some light on the relation between surface reactivity and solubility of $\mathrm{ThO}_{2}(\mathrm{cr})$. ThO $(\mathrm{cr})$ particles used are spherical with an average diameter of $500 \mu \mathrm{m}$. These spheres are originating from TRISOcoated (Tri-isotropic or multi-layered high- and low-density pyrolytic carbon and silicon carbide coatings) fuel particles of the german HTR (High Temperature Reactor) test programme. In fact, only a few data exist concerning dissolution properties of these spheres $[15,16]$. We have chosen these materials because they were made using a well defined protocol [17] allowing to obtain spherical solid samples with similar and strictly controlled surface. In this work, we have examinated, in a first part, the dissolution properties of these particles and, in a second part, the role of surface reactivity in the establishment of dynamic solubility equilibria.

The present work is a part of a large project on solubility/surface properties of oxides including $\mathrm{ThO}_{2}(\mathrm{cr})$ and $\mathrm{ZrO}_{2}(\mathrm{cr})$ with the aim of establishing a database of thorium oxide dissolution with detailed description of surface properties of each solid. The work described in this paper focuses mainly on aqueous dissolution of ${ }^{232} \mathrm{ThO}_{2}(\mathrm{cr})$ in acidic media and sorption properties of reacted surface with respect to ${ }^{229}$ Th isotope at close-to-equilibrium conditions. This approach leads to qualitative and quantitative informations about ${ }^{232} \mathrm{ThO}_{2}$ (cr) surface properties. Detailed characterization of the $\mathrm{ThO}_{2}(\mathrm{cr})$ surface is still going on and will be published elswhere.

Author

J.Vandenborre1)*,

A.Abdelouas1)

B.Grambow1)
Title

Discrepancies in thorium oxide solubility values: a new experimental approach to improve understanding of oxide surface at solid/solution interface

$\begin{array}{lll}\text { File Name } & \text { Date } & \text { Page } \\ \text { Vandenborre_RCA } & 26.06 .2008 & 2(13)\end{array}$




\section{Experimental}

The preparation of the received $\mathrm{ThO}_{2}(\mathrm{cr})$ spheres was described in [17] using a calcination temperature of $1600^{\circ} \mathrm{C}$. Physical data of the spheres are given in Table 1 . Batch dissolution experiments with 150 of these spheres were conducted in $15 \mathrm{ml}$ of $0.01 \mathrm{M} \mathrm{NaCl}$ solution in HDPE containers at room temperature under continous agitation. The $\mathrm{pH}$ was adjusted to either 3.0 or 4.0 by addition of a $0.1 \mathrm{M} \mathrm{HCl}$ solution. The ratio "spheres surface area/solution volume" was $8 \mathrm{~m}^{-1}$. The dissolution kinetics of $\mathrm{ThO}_{2}$ (cr) were followed by sampling aliqots of $0.5 \mathrm{ml}$ every 10 days over a period of 270 days. The solution samples were ultrafiltrated with $1.8 \mathrm{~nm}$ cutoff membranes ( $5 \mathrm{kDa}$ ) in order to exclude colloidal particles commonly described in the literature [1, 9]. The ultrafiltrated solutions were then analyzed by ICP-MS for the determination of ${ }^{232} \mathrm{Th}$ concentration in solution $\left.\left({ }^{232} \mathrm{Th}\right]_{\mathrm{aq}}\right)$ with an estimated error of $\pm 10 \%$. For ${ }^{229} \mathrm{Th}$, aliqots were measured directly without ultrafiltration by $\alpha$ spectrometry (error $\pm 10 \%$ ) after deposition of solution on a stainless steel counting plate and calcination at $500^{\circ} \mathrm{C}$ for 12 hours.

Table 1 : $\mathrm{ThO}_{2}$ (cr) spheres specifications [16]

\begin{tabular}{ll}
\hline Sphere & $\mathrm{ThO}_{2}(\mathrm{cr})$ \\
\hline Diameter $(\mathrm{mm})$ & 0.5 \\
Weight $(\mathrm{mg})$ & 0.69 \\
Density $\left(\mathrm{g} \mathrm{cm}^{-3}\right)$ & 10.00 \\
Specific area $\left(\mathrm{m}^{2} \mathrm{~g}^{-1}\right)$ & $1.2 \times 10^{-3}$ \\
One sphere area $\left(\mathrm{m}^{2}\right)$ & $0.8 \times 10^{-6}$ \\
\hline
\end{tabular}

The geometrical surface area (Table 1) of the spheres was used as reference, because it is too low to be measured by gas adsorption methods. In many cases, geometric surface area estimations of ceramics are good estimates of experimental values [15].

Prior to the dissolution experiments, some $\mathrm{ThO}_{2}(\mathrm{cr})$ spheres were pre-washed with a $0.1 \mathrm{M} \mathrm{HCl}$ solution for 15 days and then with deionized water to remove tiny and easily leachable particles that may interfere with solubility measurements as indicated in the literature [2, 3]. Other spheres where used without prewashing. The dissolution experiment is then conducted in three steps:

Step 1: leaching $150 \mathrm{ThO}_{2}$ (cr) spheres in solutions of either $\mathrm{pH} 3.0$ or 4.0 for 130 days to reach a steady state ${ }^{232}$ Th-concentration of about $1 \times 10^{-6} \mathrm{M}$ at pH 3.0 and $2 \times 10^{-7} \mathrm{M}$ at pH 4.0 .

Step 2: After having confirmed the establishment of the steady state for about a month, at day 155, we added a ${ }^{229}$ Th containing solution $\left(\mathrm{t}_{1 / 2}=7340\right.$ years, $\left.\mathrm{E} \alpha=4,845 \mathrm{MeV}\right)\left({ }^{229} \mathrm{Th}\right.$ in $\left.3 \mathrm{M} \mathrm{HNO}_{3}\right)$ to follow the potentially

B.Grambow1)
Title

Discrepancies in thorium oxide solubility values: a new experimental approach to improve understanding of oxide surface at solid/solution interface 
ongoing solution/surface exchange on the $\mathrm{ThO}_{2}(\mathrm{cr})$ surface. Inmediately after addition of the acid ${ }^{229} \mathrm{Th}$ aliquot, the acid perturbation of the solution $\mathrm{pH}$ was compensated by addition of $0.1 \mathrm{M} \mathrm{NaOH}$ until the target $\mathrm{pH}$ values of either 3.0 or 4.0 where reached again. An additional blank experiment was performed in parallel in the same experimental conditions but without the presence of the solid phases. These experiments have confirmed that the addition procedure in the step 2 did not imply local Th precipitation by $\mathrm{pH}$ adjusting.

Step 3: At day 209, we added 150 fresh $\mathrm{ThO}_{2}$ (cr) spheres to the system to check whether the observed steady state represents a true thermodynamic equilibrium and whether solid/solution exchange processes are still active or whether it corresponds to some kind of surface passivation. These experiments without $\mathrm{ThO}_{2}(\mathrm{cr})$ spheres but with ${ }^{229}$ Th showed no sorption on wall containers.

\section{Results}

\section{Thorium speciation in solution}

Calculations of speciation in $0.01 \mathrm{M} \mathrm{NaCl}$ solution were performed with the geochemical code PHREEQC [18] using the themodynamic data for Th hydrolysis of Neck et al. [12]. At pH 3 about 56\% $\mathrm{Th}^{4+}$ and $44 \% \mathrm{ThOH}^{3+}$ are expected to be formed. For $\mathrm{pH} 4.0$, about $67 \% \mathrm{ThOH}^{3+}, 23 \% \mathrm{Th}(\mathrm{OH})_{2}{ }^{2+}$ and $10 \% \mathrm{Th}^{4+}$ are predicted.

\section{2. $\mathrm{ThO}_{2}$ (cr) spheres leaching study}

Dissolution and precipitation kinetics of ${ }^{232} \mathrm{Th}$ were expressed by the normalized elemental mass loss as a function of time. The normalised elemental mass loss is calculated using the following formula :

$$
\mathrm{NLi}=\frac{\mathrm{CTh} \times \mathrm{fC}}{\mathrm{SA} / \mathrm{V}}
$$

where $\mathrm{C}_{\mathrm{Th}}(\mathrm{M})$ is the concentration of ${ }^{232} \mathrm{Th}$ in solution, $\mathrm{SA} / \mathrm{V}$ the $\mathrm{ThO}_{2}$-surface-area-to-solution-volume ratio $\left(\mathrm{m}^{-1}\right)$ and fc is a conversion factor of masses from the element to the oxide. The result is expressed in $\mathrm{g} \mathrm{m}^{-2}$.

$$
\mathrm{fc}=\frac{\text { molar mass of the oxide }}{\text { atomic mass of the element }}
$$

NL values can be converted directly to an average equivalent depth of the dissolution front in the solid, simply by dividing it by the materials density.

The thorium oxide dissolution rate $\left(\mathrm{g} \mathrm{m}^{-2} \mathrm{~d}^{-1}\right)$ depending on the normalized mass loss, is defined by :

Title

Discrepancies in thorium oxide solubility values: a new experimental approach to improve understanding of oxide surface at solid/solution interface 


$$
\mathrm{NLR}_{\mathrm{i}}=\frac{\mathrm{dNL}_{\mathrm{i}}}{\mathrm{dt}}
$$

The results of the dissolution experiments of $\mathrm{ThO}_{2}(\mathrm{cr})$ are given in figure 1 as the normalized mass loss of Th ( $\mathrm{NL}$ in $\mathrm{g} \mathrm{m}^{-2}$ ) as a function of time. Three sets of experiments are given in figure 1 (A, B, C) as described in table 2. Experiment A was conducted at $\mathrm{pH} 3.0$ using pre-washed $\mathrm{ThO}_{2}(\mathrm{cr})$ spheres. Experiments $\mathrm{B}$ and $\mathrm{C}$ were realised at $\mathrm{pH} 3.0$ and 4.0, respectively, without pre-washing the spheres. At $\mathrm{pH}$ 4.0, steady state was reached after about 70 days. Table 2 clearly shows that at $\mathrm{pH} 3.0$ pre-washing had no effect on $\mathrm{ThO}_{2}(\mathrm{cr})$ dissolution with saturation values of about $(1.2 \pm 0.1) \times 10^{-6} \mathrm{M}$ reached after about 100 days. At $\mathrm{pH} 4.0$, the NL(Th) was about one order of magnitude lower than that at pH 3.0, in good agreement with solubility data given in literature [14].

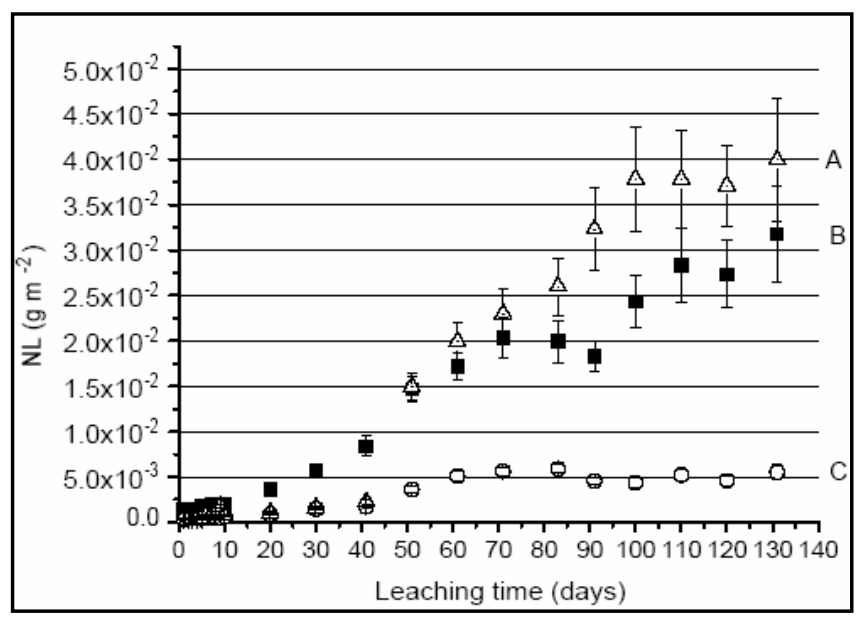

Figure 1: Normalized mass loss values versus contact time, (A) pH 3.0 + spheres pre-washed, (B) $\mathrm{pH} 3.0$, (C) $\mathrm{pH} 4.0$

Concerning concentration values of the released Th in solution, we compare the steady state concentrations of this work (130 day data) with concentrations reported in the literature as "solubility" values [14]. Our results for $\mathrm{pH} 3.0\left(\left[{ }^{232} \mathrm{Th}\right]=(1.1 \pm 0.1) \times 10^{-6} \mathrm{M}\right)$ and $\mathrm{pH} 4.0\left(\left[\left[^{232} \mathrm{Th}\right]=(1.5 \pm 0.2) \times 10^{-7} \mathrm{M}\right)\right.$ are similar to "solubility" values reported in the litterature for crystallized $\mathrm{ThO}_{2}(\mathrm{cr})$ powders $[9,21,22]$. Since the steady state concentrations of our spheres are similar to literature "solubility" values, one can conclude that following investigation of surface/solution exchange properties in step 2 and 3 are a direct test as to whether a real solubility equilibrium has been achieved in the case of literature data.

Table 2: Data of $\mathrm{ThO}_{2}(\mathrm{cr})$ spheres leaching experiments

\begin{tabular}{lllll}
\hline Samples & pH & pre-washed & $\begin{array}{l}\mathrm{NL}\left(\mathrm{g} \mathrm{m}^{-2}\right) \\
\mathrm{t}=130 \mathrm{~d}\end{array}$ & $\begin{array}{l}\left.{ }^{232} \mathrm{Th}\right](\mathrm{M}) \\
\mathrm{t}=130 \mathrm{~d}\end{array}$ \\
\hline A & 3.0 & HCl 0.1 M & $3.8 \times 10^{-2}$ & $1.2 \times 10^{-6}$ \\
$\mathrm{~B}$ & 3.0 & None & $2.8 \times 10^{-2}$ & $1.0 \times 10^{-6}$ \\
$\mathrm{C}$ & 4.0 & None & $5.5 \times 10^{-3}$ & $1.5 \times 10^{-7}$ \\
\hline
\end{tabular}

Author

J.Vandenborre1)*,

A.Abdelouas1)

B.Grambow1)
Title

Discrepancies in thorium oxide solubility values: a new experimental approach to improve understanding of oxide surface at solid/solution interface

$\begin{array}{lll}\text { File Name } & \text { Date } & \text { Page } \\ \text { Vandenborre_RCA } & 26.06 .2008 & 5(13)\end{array}$ 
Table 3 recapitulates calculated normalized dissolution rate (NLR in $\mathrm{g} \mathrm{m}^{-2} \mathrm{~d}^{-1}$ ). Two breaks on (NL vs. time) curves are detected: 1$)$ for experiment $A\left(N_{1 A}=0.4 \times 10^{-4} \mathrm{~g} \mathrm{~m}^{-2} \mathrm{~d}^{-1}\right.$ and $\left.\mathrm{NLR}_{2 \mathrm{~A}}=5.2 \times 10^{-4} \mathrm{~g} \cdot \mathrm{m}^{-2} \mathrm{~d}^{-1}\right)$ between the $40^{\text {th }}$ and the $50^{\text {th }}$ day; 2$)$ for experiment $B\left(\mathrm{NLR}_{1 \mathrm{~B}}=2.7 \times 10^{-4} \mathrm{~g} \cdot \mathrm{m}^{-2} \mathrm{~d}^{-1}\right.$ and $\left.\mathrm{NLR}_{2 \mathrm{~B}}=5.2 \times 10^{-4} \mathrm{~g} \mathrm{~m}^{-2} \mathrm{~d}^{-1}\right)$ between the $90^{\text {th }}$ and the $100^{\text {th }}$ day. Normalized dissolution rates determined in this work are consistent with previous results from this laboratory [16]. Moreover, $\mathrm{NLR}_{2 \mathrm{~A}}$ and $\mathrm{NLR}_{2 \mathrm{~B}}$ values are identical, so we think, it is the same surface configuration that controls the dissolution rate for the solid leached with a pH 3.0 solution.

In experiment $\mathrm{A}$, prior to 40 days, the extent of dissolution correspond to $\mathrm{NL}=2 \times 10^{-3} \mathrm{~g} \cdot \mathrm{m}^{-2}$ or an average depth of the dissolution front of $0.2 \mathrm{~nm}$, the dimension of a mono-layer. Between 40 and 50 days, an NL value of $1.5 \times 10^{-2} \mathrm{~g} \cdot \mathrm{m}^{-2}$ or a dissolution depth of $1.5 \mathrm{~nm}$ is achieved, corresponding to the dissolution of 3 unit cells. For experiment B, after a somewhat monotoneous rise, a plateau value of $2 \times 10^{-2} \mathrm{~g} \cdot \mathrm{m}^{-2}$ is observed corresponding to dissolution of 4 unit cells before disolution continues again with higher rates. Steady state concentrations are achieved after dissolving 3-4 nm.

Table 3 : Normalized dissolution rates from $\mathrm{ThO}_{2}(\mathrm{cr})$ spheres leaching experiments

\begin{tabular}{llll}
\hline \multicolumn{2}{l}{ Samples } & Contact time (d) & NLR $\left(\mathrm{g} \mathrm{m}^{-2} \mathrm{~d}^{-1}\right)$ \\
\hline \multirow{2}{*}{$\mathrm{A}$} & $\mathrm{NLR}_{1 \mathrm{~A}}$ & $0-40$ & $0.4 \times 10^{-4}$ \\
& $\mathrm{NLR}_{2 \mathrm{~A}}$ & $40-90$ & $5.2 \times 10^{-4}$ \\
\hline \multirow{2}{*}{$\mathrm{B}$} & $\mathrm{NLR}_{1 \mathrm{~B}}$ & $0-70$ & $2.7 \times 10^{-4}$ \\
& $\mathrm{NLR}_{2 \mathrm{~B}}$ & $90-110$ & $5.2 \times 10^{-4}$ \\
\hline $\mathrm{C}$ & $\mathrm{NLR}_{\mathrm{C}}$ & $0-50$ & $0.5 \times 10^{-4}$ \\
\hline
\end{tabular}

\section{3. ${ }^{229} \mathrm{Th}$ isotope addition and fresh $\mathrm{ThO}_{2}(\mathrm{cr})$ addition}

We continued the leaching test with step 2 and 3 (see “experimental”) in the case of experiment B, corresponding to a $\mathrm{pH}$ of 3.0. Figure 2 presents results obtained with experiment $\mathrm{B}$ before and after addition of ${ }^{229}$ Th. This figure shows two curves: ${ }^{232}$ Th concentration measured by ICP-MS and ${ }^{229}$ Th concentration measured by $\alpha$ spectrometry versus contact time. Notice that it exists a factor $10^{3}$ between the two y-scales for visibility reasons. These curves can be divided in three distinct steps:

1) $\mathbf{t}=\mathbf{0} \mathbf{d}$ : Leaching experiment start (150 spheres $\mathrm{ThO}_{2}(\mathrm{cr})+\mathrm{pH} 3.0$ leaching solution)

2) $\mathbf{t}=\mathbf{1 5 5} \mathbf{d}:{ }^{229} \mathrm{Th}$ isotope addition + leaching solution adjustment to $\mathrm{pH} 3.0$

3) $\mathbf{t}=\mathbf{2 0 9} \mathbf{d}$ : Addition of $150 \mathrm{ThO}_{2}(\mathrm{cr})$ spheres

Author

J.Vandenborre1)*,

A.Abdelouas1)

B.Grambow1)
Title

Discrepancies in thorium oxide solubility values: a new experimental approach to improve understanding of oxide surface at solid/solution interface $\begin{array}{lll}\text { File Name } & \text { Date } & \text { Page } \\ \text { Vandenborre_RCA } & 26.06 .2008 & 6(13)\end{array}$ 


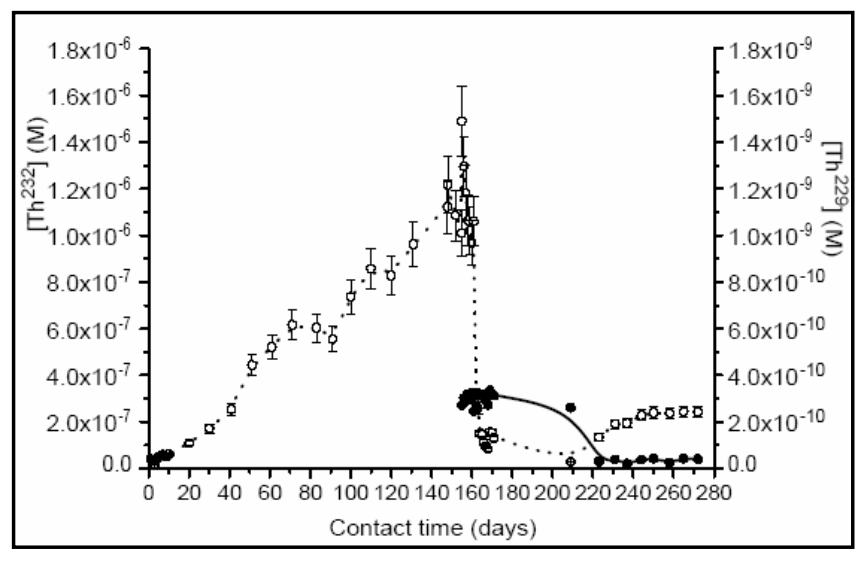

Figure 2 : Sample B leaching experiment, dashed line and white spots for $\left[\mathrm{Th}^{232}\right]$ (left $\mathrm{y}$-scale), solid line and black spots for $\left[\mathrm{Th}^{229}\right]$ (right y-scale)

After reaching the steady state in step 1 at a value of $\left[{ }^{232} \mathrm{Th}\right]=(1.0 \pm 0.1) \times 10^{-6} \mathrm{M}$, the addition of a spike of ${ }^{229} \mathrm{Th}$ (step 2) at 155 days leads to a strong reduction of solution concentrations even though the $\mathrm{pH}$ is kept constant.

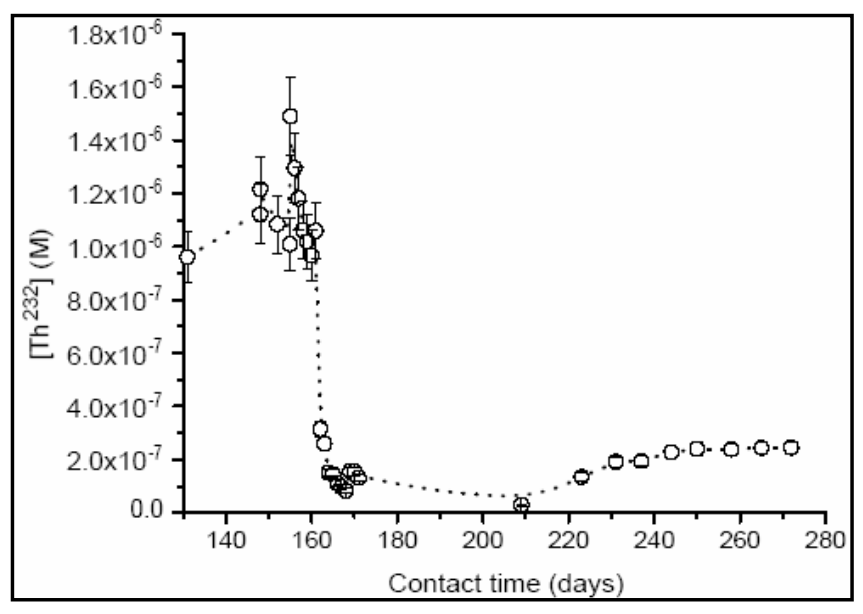

Figure 3: Detailed [ $\left.{ }^{232} \mathrm{Th}\right]$ vs. contact time of B leaching experiment

Figure 3 shows a detail of figure 2 immediatly before and after this addition which is indicated by a sharp rise and sudden fall of ${ }^{232} \mathrm{Th}$ concentration. After ${ }^{229} \mathrm{Th}$ addition, the ${ }^{229} \mathrm{Th}$ concentrations stayed constant during 60 days even though ${ }^{232} \mathrm{Th}$ heavily precipitated with a final concentration of about $\left[{ }^{232} \mathrm{Th}\right]=(1.6 \pm 0.2) \times 10^{-7} \mathrm{M}$. ${ }^{232} \mathrm{Th}$ likely precipitates as tiny colloids of $\mathrm{ThO}_{2}(\mathrm{~s}$, hyd) [23]. Colloid particles have been separated by ultrafiltration prior to ${ }^{232} \mathrm{Th}$ measurement but ${ }^{229} \mathrm{Th}$ measurements in non-filtered solutions include this potential colloidal fraction. ${ }^{229} \mathrm{Th}$ might "co"precipitate with freshly formed ${ }^{232} \mathrm{ThO}_{2}\left(\mathrm{~s}\right.$, hyd) colloids. The ${ }^{232} \mathrm{Th}$ concentration diminished within 60 days (total contact time 209 days) to a final value of $(2.9 \pm 0.3) \times 10^{-8} \mathrm{M}$ until addition of fresh $\mathrm{ThO}_{2}$ (cr) spheres, which start to dissolve as indicated by the increase of ${ }^{232} \mathrm{Th}$ experimental approach to improve understanding of oxide 
concentration in solution until a steady state of $(2.4 \pm 0.2) \times 10^{-7} \mathrm{M}$. In the mean time, ${ }^{229}$ Th concentration starts to decrease from $(3.0 \pm 0.3) \times 10^{-10} \mathrm{M}$ to $(3.5 \pm 0.3) \times 10^{-11} \mathrm{M}$.

\section{Discussion}

Prior to reaching the "final” steady state value from undersaturated conditions, dissolution of $\mathrm{ThO}_{2}(\mathrm{cr})$ appears to proceed in a stepwise mode: initial slow dissolution followed by acceleration, slow-down again, reacceleration and approach of steady state. The fast process correspond to unhindered dissolution of many mono-layers on $\mathrm{ThO}_{2}$, and the slow-down may relate to some inhibition process which may occur at not forseable moments. If each surface atom would have a similar probability to become detached until at steady state, attachment and detachment rates become equal at steady state and such behavior would be impossible. A fast initial rate would monotonously slow down until reaching saturation like in a first order dissolution process. The present observation of the dissolution process indicates that surface atom detachment during dissolution does not proceed simultaneously in a statistic fashion all across the surface but it proceeds at few specific sites ("high energy sites”) for example analogous to spiral growth in case of crystal growth in an inverse manner at specific retreating fronts at steps on the surface. The question is now whether the observed steady state value has any thermodynamic significance or whether it is just another plateau value.

Figure 4 shows a comparison of our steady state/solubility values in steps 1-3 with literature data for $0.5 \mathrm{M} \mathrm{NaCl}$ or $\mathrm{NaClO}_{4}$ solutions. Included are two model curves for the solubility of colloidal $(20 \mathrm{~nm}) \mathrm{ThO}_{2}(\mathrm{cr})$ in either 0.5 $\mathrm{M}$ or $0.01 \mathrm{M} \mathrm{NaCl}$. The thermodynamic data of Neck et al. [12] were used for this purpose together with the geochemical code PHREEQC.

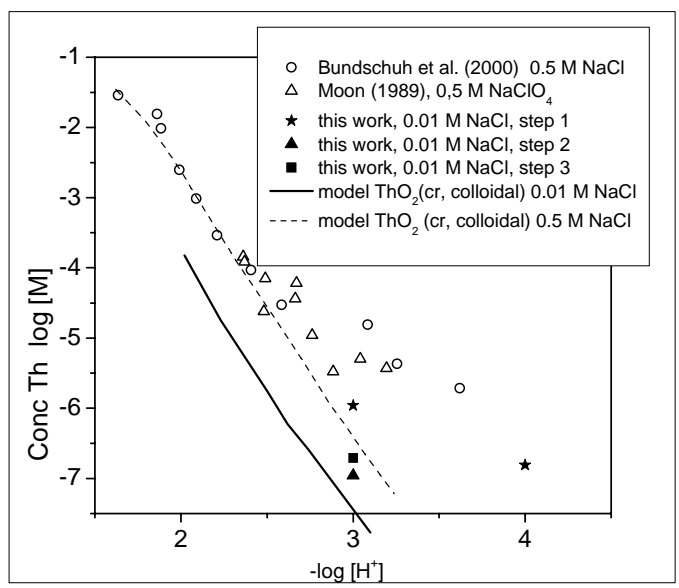

Figure 4: Comparison solubility values between our study and literature [9, 22]

Author

J.Vandenborre1)*,

A.Abdelouas1)

B.Grambow1)
Title

Discrepancies in thorium oxide solubility values: a new experimental approach to improve understanding of oxide surface at solid/solution interface

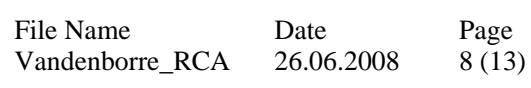


It can be seen, in agreement with the calculations by Neck et al. [12] that for pH values higher than 2.5, that the reported experimental data in $0.5 \mathrm{M} \mathrm{NaCl}$ are higher than the calculated solubility curve for $0.5 \mathrm{M} \mathrm{NaCl}$. This deviation was already described and explained by Neck et al. [14] to the presence of a possibly non-detectable amorphous phase governing solubility. Our steady state results from step 1 are similar or even slightly lower than these literature solubility data. Indeed a lower solubility of $\mathrm{ThO}_{2}(\mathrm{cr}, 20 \mathrm{~nm})$ is expected in $0.01 \mathrm{M} \mathrm{NaCl}$ when compared to the solubility in $0.5 \mathrm{M} \mathrm{NaCl}$. This saturation state has been reached after dissolving the surface to a depth of about 3-4 nm with a rate of about $5 \cdot \times 10^{-4} \mathrm{~g} \cdot \mathrm{m}^{-2} \mathrm{~d}^{-1}$ corresponding to a surface detachement rate of $0.05 \mathrm{~nm} \mathrm{~d}^{-1}$. Hence, the surface is entirely reconstructed prior to reaching this saturation state.

The geometric constraints of our dissolution experiments are quite different from the previously reported solubility studies where powders or colloids have been used as solid phase implying that less than a monolayer was dissolved to reach the steady state. Hubert et al. [3] observed with powdered $\mathrm{ThO}_{2}(\mathrm{cr})$ a dissolution rate of $2.5 \cdot \times 10^{-8} \mathrm{~g} \cdot \mathrm{m}^{-2} \mathrm{~d}^{-1}$ at $\mathrm{pH} 3.1$, about $10^{4}$ times lower than our rate. In that case, dissolution of a monolayer would have taken 300 years. It is likely that local surface passivation may have reduced the rate in the case of Hubert et al.

The decrease of ${ }^{232} \mathrm{Th}$ concentrations in step 2 confirms that the saturation state in step 1 is a highly supersaturated (metastable) state. This leads to an important conclusion from step 1: $\mathrm{ThO}_{2}(\mathrm{cr})$ either continues to dissolve even if the solution is highly supersaturated, or the solubility of this type of $\mathrm{ThO}_{2}(\mathrm{cr})$ is higher than that of the precipitated colloids. The fact that 3-4 $\mathrm{nm}$ of the crystalline material dissolved to reach steady state also indicates that it is not amorphous hydrous $\mathrm{ThO}_{2}$ which controls the steady state concentration. Achievement of a true equilibrium state is clearly blocked by hindering the back reaction. A possible reason might be missing nucleation sites for the back-reaction. Addition of ${ }^{229} \mathrm{Th}$ might have brought an end to critical supersaturation concentrations (see peak in figure 3) through precipitation of colloidal ${ }^{232} \mathrm{ThO}_{2}$ (s, hyd).

The establishment of a solubility equilibrium might involve a dynamic steady state of equal forward and backward reaction rates. However, in the second part (step 2), such an exchange reaction between the surface $\left({ }^{232} \mathrm{Th}\right)$ and solution $\left({ }^{229} \mathrm{Th}\right)$ could not be detected because ionic $\left[{ }^{232} \mathrm{Th}\right]$ values decrease while potential colloidal $\left[{ }^{229} \mathrm{Th} /\right.$ and probably $\left.{ }^{232} \mathrm{Th}\right]$ values remain constant for over 60 days at about their initial concentration. Rapid formation of colloidal ${ }^{229} \mathrm{ThO}_{2}$ (s, hyd) may have masked this exchange.

At step 3, the reinitiation of the dissolution process by addition of fresh spheres indicates 1) that the precipitated colloidal phase from step 2 must have a lower solubility than the dissolving $\mathrm{ThO}_{2}(\mathrm{cr})$ sphere and 2) that the spheres remaining from step 1 behave entirely passive. We conclude that there are no active sites on the spheres

Author

J.Vandenborre1)*,

A.Abdelouas1)

B.Grambow1)
Title

Discrepancies in thorium oxide solubility values: a new experimental approach to improve understanding of oxide surface at solid/solution interface $\begin{array}{lll}\text { File Name } & \text { Date } & \text { Page } \\ \text { Vandenborre_RCA } & 26.06 .2008 & 9(13)\end{array}$ 
from step 1 (or detachement of active sites is inhibited) but on the fresh particles from step 3, new active sites for dissolution exist. A new steady state is achieved with ${ }^{232}$ Th values of $(2.4 \pm 0.2) \times \cdot 10^{-7} \mathrm{M}$ corresponding to a detachment of at least 2.5 mono-layers on the added particles. Both, this new steady state and the saturation concentration achieved after precipitation in step 2 correspond to solubility values at pH 3 are still slightly higher then the theoretical solubility curve for $\mathrm{ThO}_{2}(\mathrm{cr}, 20 \mathrm{~nm})$ in figure 4 . This may indicate that colloidal particles with a diameter $<20 \mathrm{~nm}$ control solubility. It is interesting to note that the dissolution of ${ }^{232}$ Th is accompanied by an adsorption of $4.0 \times 10^{-12}$ moles of ${ }^{229} \mathrm{Th}$. This indicates the establishment of some kind of dynamic exchange or a surface precipitation of ${ }^{229}$ Th colloids formed during the second step. Considering the isotopic ratio ${ }^{229} \mathrm{Th} /{ }^{232} \mathrm{Th}$ of 0.0088 immediately prior to addition of $150 \mathrm{ThO}_{2}(\mathrm{cr})$ particles, the adsorption of ${ }^{229} \mathrm{Th}$ colloids corresponds to adsorption of $4.5 \times 10^{-10}$ moles of ${ }^{232}$ Th or about $1 / 3$ of a mono-layer. Hence we can conclude on a dynamic exchange balance involving 2.8 monolayers with a total dissolution of 2.5 monolayers and a reconstitution of 0.3 monolayers with ${ }^{229} \mathrm{ThO}_{2}$ (s, hyd) colloids adsorption. However, as before in step 2, once the saturation rate is achieved, the isotopic exchange seems to stop as well. This might either indicate that the equilibrium state is associated with an inhibition of active sites on the surface or that exchange still continues but that the isotopic composition of the equilibrium surface equals that in solution.

The comparison of the isotopic ratios $\left({ }^{229} \mathrm{Th} /{ }^{232} \mathrm{Th}\right)$ at the surface and in solution at test termination gives additional information on the establishment of this equilibrium. If this ratio in solution would be higher than at the surface, we might assume that less than a monolayer is involved in the establishment of a solubility equilibrium. We calculated the isotopic ratio of the surface concentrations of ${ }^{229} \mathrm{Th}$ and ${ }^{232} \mathrm{Th}$ by assuming that all ${ }^{229}$ Th lost from solution in step 3 is incorporated into the surface. The calculation shows that the isotopic ratio at the surface is about 23 times larger than that in solution. This would either indicate that about 23 mono-layers would be implied in a dynamic solubility equilibrium or it indicates more likely that ${ }^{229}$ Th containing colloids are fixed on solid surfaces after addition of $\mathrm{ThO}_{2}(\mathrm{cr})$ particles.

Our experimental results cannot be explained by a simple macroscopic $(4-n)^{\text {th }}$ order dissolution rate law linking kinetic constraints and solubility constants which might be formulated in a general way like:

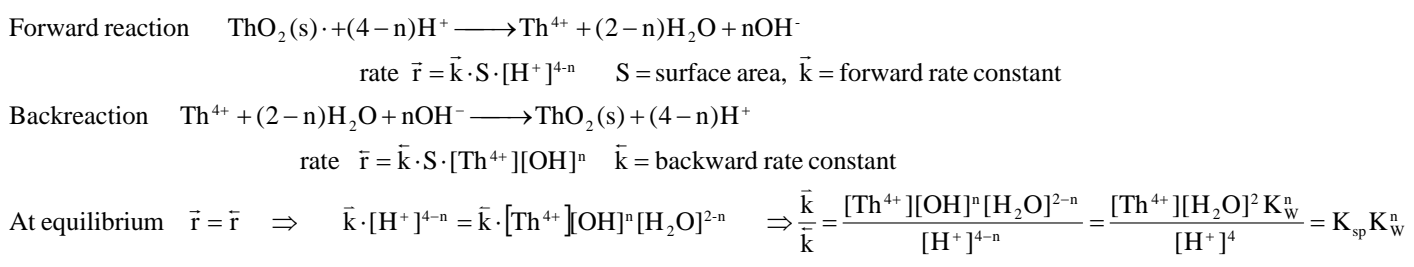
experimental approach to improve understanding of oxide surface at solid/solution interface 
From the work of Heisbourg et al. [24] we deduce a value of $n=3.74$, from our limited data between pH 3 and 4 a value of $n=3.0$. Such rate law has first been applied to mineral dissolution in a more simple way by Rimstid and Barnes [25] for $\mathrm{SiO}_{2}$. It implies that the forward and backward rate constants remain constant and similar even at saturation conditions and only the overall rate becomes zero. Instead, from the observed passive behaviour of $\mathrm{ThO}_{2}(\mathrm{cr})$ particles in step 2 and the active dissolution of new particles in step 3, it becomes clear that not only the overall rate but as well the forward rate decreases at saturation, a phenomena for which we used the term "passivation”. This passivation may well be the result of a loss or blocking of reactive surface sites. An active site might be a kink site or a crystallographic step on the surface. Dissolution might occur by step retreat similar as observed on calcite surfaces [26]. A more adequate rate law would have to account for the change of such active site density and/or step retreat rates when approaching equilibrium.

\section{Conclusion}

This paper deals with the $\mathrm{ThO}_{2}(\mathrm{cr})$ solubility value determination and the likely relationship between surface properties and dissolution behaviour for this oxide. This work gives some insights about the system solid/solution considered:

o $\quad \mathrm{ThO}_{2}(\mathrm{cr})$ spheres have all similar surfaces and so leaching results are reproducible for all samples. It is a strong difference with other data from literature found for different powders with different structure and then different surface properties induced by different synthesis conditions.

o We have provided evidence that the $\mathrm{ThO}_{2}(\mathrm{cr})$ dissolution reaction is induced by surface and bulk phenomena for $\mathrm{pH}$ 3.0. Similar results have been published for $\mathrm{ThO}_{2}(\mathrm{cr})$ dissolution in neutral and alkaline media [1].

o Dissolution of crystalline $\mathrm{ThO}_{2}$ continues if the solution is supersaturated with respect to $\mathrm{ThO}_{2}$ colloids. This is in conflict with current understanding of solubility equilibria.

o The use of a ${ }^{229}$ Th isotope spike during the dissolution experiment demonstrated that at saturation (steady state) conditions, no dynamic exchange reactions between the aged or precipitated surface and the solution happened. This is different to what it commonly described in the literature. However, solid/solution exchange reactions occurred during dissolution of fresh surface.

Among future work, we will focus on $\mathrm{ThO}_{2}(\mathrm{cr})$ surface characterization during dissolution process and will focus on studying the chemical environment of surface atoms $\left({ }^{232} \mathrm{Th}\right.$ vs. $\left.{ }^{229} \mathrm{Th}\right)$. The final aim consists in

Author

J.Vandenborre1)*,

A.Abdelouas1)

B.Grambow1)
Title

Discrepancies in thorium oxide solubility values: a new experimental approach to improve understanding of oxide surface at solid/solution interface 
describing $\mathrm{ThO}_{2}$ dissolution mechanisms by taking account of its surface properties (active surface sites) and not only an average macroscopic solubility value.

Acknowledgements.

We are grateful to Herr Fachinger from Forschungszentrum of Jülich for providing the TRISO spheres. We thank C.Chalopin for helping in leaching experiments. The work was partly funded by project ANR SOLRAD.

\section{References}

[1]. $\quad$ Altmaier, M., Neck, V., and Fanghänel, T.: Solubility and colloid formation of Th(IV) in concentrated $\mathrm{NaCl}$ and $\mathrm{MgCl}_{2}$ solution. Radiochim. Acta. 92, 537-543 (2004).

[2]. Heisbourg, G.: Synthèse, caractérisation et études cinétique et thermodynamique de la dissolution de $\mathrm{ThO}_{2}$ et des solutions solides $\mathrm{Th}_{1-\mathrm{x}} \mathrm{M}_{\mathrm{x}} \mathrm{O}_{2}(\mathrm{M}=\mathrm{U}, \mathrm{Pu})$ in Université Paris XI. thesis doctorat (2003).

[3]. Hubert, S., Barthelet, K., Fourest, B., Lagarde, G., Dacheux, N., and Baglan, N.: Influence of the precursor and the calcination temperature on the dissolution of thorium dioxide. Journal of Nuclear Materials. 297, 206-213 (2001).

[4]. Jernström, J., Vuorinen, U., and Hakanen, M.: Solubility of thorium in $0.1 \mathrm{M} \mathrm{NaCl}$ solution. report 2000-17. (2000).

[5]. Östhols, E.: The solubility of microcrystalline $\mathrm{ThO}_{2}$ in phosphate media. Radiochim. Acta. 788, 1-6 (1995).

[6]. Jernström, J., Vuorinen, U., and Hakanen, M.: Solubility of thorium in $0.1 \mathrm{M} \mathrm{NaCl}$ solution and in saline and fresh anoxic reference groundwater. report 2002-06. (2002).

[7]. Rai, D., Moore, D.A., Oakes, C.S., and Yui, M.: Thermodynamic model for the solubility of thorium dioxide in the $\mathrm{Na}^{+}-\mathrm{Cl}^{-}-\mathrm{OH}^{-}-\mathrm{H}_{2} \mathrm{O}$ system at $23^{\circ} \mathrm{C}$ and $90^{\circ} \mathrm{C}$. Radiochim. Acta. 88, 297-306 (2000).

[8]. Wierczinski, B., Helfer, S., Ochs, M., and Skarnemark, G.: Solubility measurements and sorption studies of thorium in cement pore water. Journal of Alloys and Compounds. 271-273, 272-276 (1998).

[9]. Bundschuh, T., Knopp, R., Müller, R., Kim, J.I., Neck, V., and Fanghänel, T.: Application of LIBD to the determination of the solubility product of thorium (IV)-colloids. Radiochim. Acta. 88, 625-629 (2000).

[10]. Altmaier, M., Neck, V., Müller, R., and Fanghänel, T.: Solubility of $\mathrm{ThO}_{2} \cdot \mathrm{xH}_{2} \mathrm{O}(\mathrm{am})$ in carbonate solution and the formation of ternary Th(IV) hydroxide-carbonate complexes. Radiochim. Acta. 93, 8392 (2005).

[11]. Felmy, A.R., Rai, D., and Mason, M.J.: The solubility of hydrous thorium(IV) oxide in chloride media : development of an aqueous ion-interaction model. Radiochim. Acta. 55, 177-185 (1991).

[12]. Neck, V., Müller, R., Bouby, M., Altmaier, M., Rothe, J., Denecke, M.A., and Kim, J.I.: Solubility of amorphous Th(IV) hydroxide - application of LIBD to determine the solubility product and EXAFS for aqueous speciation. Radiochim. Acta. 90, 485-494 (2002).

[13]. Rai, D., Felmy, A.R., Sterner, S.M., Moore, D.A., and Mason, M.J.: The solubility of Th(IV) and U(IV) hydrous oxides in concentrated $\mathrm{NaCl}$ anf $\mathrm{MgCl}_{2}$ solutions. Radiochim. Acta. 79, 239-247 (1997).

[14]. Neck, V. and Kim, J.I.: Solubility and hydrolysis of tetravalent actinides. Radiochim. Acta. 9, 1-16 (2001).

[15]. Alliot, C., Grambow, B., and Landesman, C.: Leaching behaviour of unirradiated high temperature reactor (HTR) $\mathrm{UO}_{2}-\mathrm{ThO}_{2}$ mixed oxides fuel particles. Journal of Nuclear Materials. 346, 32-39 (2005).

[16]. Landesman, C., Delaunay, S., and Grambow, B.: Leaching behavior of unirradiated high temperature reactor (HTR) $\mathrm{UO}_{2}-\mathrm{ThO}_{2}$ mixed oxides fuel particles. Materials Research Society Symposium Proceeding. 807(2004).

[17]. Müller, A. Establishment of the technology to manufacture uranium dioxide kernels for PBMR fuel. in Proceedings HTR2006 : 3rd International Topical Meeting on High Temperature Reactor Technology. 2006. Johannesburg, South Africa.

[18]. Van der Lee, J., JCHESS, in software, C.d.i. Géologique, Editor. 2002, ARMINES (FRANCE).

[19]. Wolery, T., EQ3/6 : A software Package for Geochemical Modelling of Aqueous Systems: Package Overview and Installation Guide. . 1992, Lawrence Livermore National Laboratory (USA) 
[20]. Östhols, E.: Thorium sorption on amorphous silica. Geochimica et Cosmochimica Acta. 59, 1235-1249 (1995).

[21]. Baes, C.F., Meyer, N.J., and Roberts, C.E.: The Hydrolysis of Thorium(IV) at 0 and $95^{\circ}$. Inorg. Chem. 4, 518-527 (1965).

[22]. Moon, H.C.: Equilibrium ultrafiltration of hydrolized thorium (IV) solutions. Bull. Korean Chem. Soc. 10, 270 (1989).

[23]. Bitea, C., Müller, R., Neck, V., Walther, C., and Kim, J.I.: Study of the generation and stability of thorium(IV) colloids by LIBD combined with ultrafiltration. Colloids and Surfaces A: Physicochemical and Engineering Aspects. 217, 63-70 (2003).

[24]. Heisbourg, G., Hubert, S., Dacheux, N., and Purans, J.: Kinetic and thermodynamic studies of the dissolution of thoria-urania solid solutions. Journal of Nuclear Materials. 335, 5-13 (2004).

[25]. Rimstidt, J.D. and Barnes, H.L.: The kinetics of silica-water reactions. Geochimica et Cosmochimica Acta. 44, 1683-1699 (1980).

[26]. Vinson, M.D., Arvidson, R.S., and Luttge, A.: Kinetic inhibition of calcite (1 04 ) dissolution by aqueous manganese(II). Journal of Crystal Growth. 307, 116-125 (2007). 